\title{
Article \\ Pain Management Using Nano-Bio Fusion Gel in Fixed Orthodontic Therapy-Induced Gingivitis: A Split-Mouth Design Study
}

\author{
Mohammad Khursheed Alam ${ }^{1, *,+}$ () , Kiran Kumar Ganji ${ }^{1,+}{ }^{+}$, Alreshidi Meshari ${ }^{2,3}$, Srinivas Munisekhar Manay ${ }^{1}$, \\ Nafij Bin Jamayet ${ }^{4}(1)$ and Ammar A Siddiqui ${ }^{5}(\mathbb{C}$
}

1 Preventive Dentistry Department, College of Dentistry, Jouf University, Sakaka 72345, Saudi Arabia; kiranperio@gmail.com (K.K.G.); dr.srinivas.manay@jodent.org (S.M.M.)

2 Orthodontics, College of Dentistry, Hail University, Hail 2400, Saudi Arabia; dr_meshari@yahoo.com

3 Orthodontic Department, Manchester University, Salford M3 5DZ, UK

4 Division of Clinical Dentistry (Prosthodontics), School of Dentistry, International Medical University, Kuala Lumpur 57000, Malaysia; dr.nafij@gmail.com

5 Department of Preventive Dentistry, College of Dentistry, Hail University, Hail 2400, Saudi Arabia; ammarqta2002@hotmail.com

* Correspondence: mkalam@ju.edu.sa or dralam@gmail.com

† Mohammad Khursheed Alam and Kiran Kumar Ganji contributed equally and both are the 1st author.

check for updates

Citation: Alam, M.K.; Ganji, K.K.; Meshari, A.; Manay, S.M.; Jamayet, N.B.; Siddiqui, A.A. Pain

Management Using Nano-Bio Fusion Gel in Fixed Orthodontic Therapy-Induced Gingivitis: A Split-Mouth Design Study. Appl. Sci. 2021, 11, 11463. https://doi.org/ 10.3390/app112311463

Academic Editor: Gaetano Isola

Received: 9 November 2021

Accepted: 25 November 2021

Published: 3 December 2021

Publisher's Note: MDPI stays neutral with regard to jurisdictional claims in published maps and institutional affiliations.

Copyright: (c) 2021 by the authors. Licensee MDPI, Basel, Switzerland. This article is an open access article distributed under the terms and conditions of the Creative Commons Attribution (CC BY) license (https:// creativecommons.org/licenses/by/ $4.0 /)$.

\begin{abstract}
Nanotechnology-based products containing antioxidants may be effective adjuvants in the treatment of periodontal diseases. To assess the treatment effect of nano bio-fusion gel (NBFG) in pain perception (PP) in fixed orthodontic therapy-induced gingivitis (FOTIG). The gel contains propolis, vitamin $C$, and vitamin $\mathrm{E}$ in the form of nanoemulsion. Thirty-two patients were finally selected from the orthodontic clinic after assessments for FOTIG. Patients were allocated randomly into active and placebo-control groups. Patients were evaluated at three intervals (T1, T2, and T3). Pain perception using a numeric rating scale (NRS) was performed at baseline (T1), on the 7th day (T2) and on the 28th day (T3) on his/her visit to an orthodontic clinic. In the T1, T2, and T3 period, patients apply NBFG (active or placebo side) to their gingiva after brushing two times a day for 28 consecutive days. Results: The baseline data between the active or placebo group showed almost similar PP. From T1 to $\mathrm{T} 2$ and $\mathrm{T} 3$, the active or placebo-control group showed significant improvement in PP over time. Compared to placebo, the active group showed highly significant ( $p \leq 0.001, \mathrm{~T} 1$ to T2 and T2 to T3) improvement in PP. The use of NBFG is an effective means of improvement in PP of FOTIG cases.
\end{abstract}

Keywords: nano bio-fusion gel; pain perception; fixed orthodontic treatment; gingivitis

\section{Introduction}

After assessing benefits and risks to the patients, the choice of planning the fixed orthodontic treatment (FOT) should be made. Among problems during FOT, almost all of the patients suffer from pain and/or discomfort. The level of PP of the FOT patients varies in different stages [1]. During FOT, 56.8\% and 34.4\% of gingivitis reported as worldwide morbidity in adolescent and adult group [2]. D Lv et al. documented that sensitization to blunt-pressure stimuli occur in both the attached gingiva and the periodontal ligament following the insertion of an archwire in orthodontic therapy [3]. Therefore, investigators are always interested in non-invasive and consistent techniques to overcome the chances of pain occurrence due to FOTIG. Current literature suggests that, as an adjunct with routine oral hygiene, scaling and root planing non-invasive practices are applicable to treat gingivitis $[4,5]$. With meticulous maintenance of oral hygiene, these problems can be minimized. However, a number of the patients have failed to follow the oral hygiene instructions suitably, which sometimes results in irreparable impairment to the periodontal structures [6]. 
Antioxidant therapy is in its beginning stage and is the most modern approach for the treatment of periodontal disease. Products based on nanotechnology, which contain antioxidants, may be excellent supplementary approach in managing periodontal diseases. Presently, the only commercially available such product based on nanotechnology globally is NBFG, which contains propolis, vitamin C, and vitamin $E$ in nanoemulsion. The beneficial outcome of propolis along with Vitamin $C$ and $E$ and nanotechnology amplified this effect in preventing disease progression. Recent reports indicate that locally delivered NBFG gel application exhibited a significant improvement compared with scaling and root planing (SRP) alone in managing chronic periodontitis [6]. Once applied, NBFG creates a nano-bioactive protective film, resulting in increased absorption and improved clinical effectiveness and visible results after application. Alam and Kiran et al. (2021) found favorable clinical outcome in FOT using NBFG [7]. Several modalities are available for treating gingivitis during orthodontic therapy such as ozone and probiotics $[8,9]$. To date, the effect of NBFG has not been tested in PP during orthodontic therapy-induced gingivitis. Thus, this study aimed to assess the clinical effectiveness of locally delivered NBF gel as adjunctive therapy to SRP in pain perception in FOTIG.

\section{Materials and Methods}

The details of each component of materials and methods are shown in Table 1. A present split-mouth design and triple-blinded study was conducted on cases of FOTIG, particularly on Saudis with the age group of 14 and 25 years. Thirty-two enrolled participants received therapy for reducing pain during orthodontic therapy using active and placebo gel applied simultaneously on the right and left side of dentition as per the allocation using a coin toss method. Initially, investigators coded the active and placebo gel. Participants were blinded, and were neither aware of division of the active and place groups nor the split-mouth design. NBFG containing propolis, vitamin C, and vitamin E was used as an active gel. Dental assistants who were also blinded with the gel information applied the gel for the participants as a demonstration process. Later, the participants continued the same application process. Training continued until the application process was $100 \%$ up to the mark. Later, the participants continued the same application process over a period of 28 days. The patients were instructed to practice normal oral hygiene routines at home, such as brushing their teeth twice daily for at least $2 \mathrm{~min}$ with a powered toothbrush (Philips Sonicare 2) and toothpaste (Colgate Total Care ${ }^{\circledR}$ ) provided to them. Operators were also blinded and did not participate in the application of the gel, collection of the data and analysis. Another assistant was involved in monitoring the application of gel by telephonically contacting participants and in the collection of the data. Analysis of the data was done by a specialist statistician after decoding the data, and the investigators were provided with results.

Table 1. Selection guideline, study population and method details.

\begin{tabular}{ccc}
\hline Selection Guideline & $\begin{array}{c}\text { Exclusive } \\
\text { Inclusive } \\
\text { Class I or II or III Angle's } \\
\text { malocclusion. }\end{array}$ & $\begin{array}{c}\text { Craniofacial abnormalities, patient on regular } \\
\text { medication, TMJ-dysfunction, parafunctional } \\
\text { habits, multiple missing teeth and } \\
\text { periodontally compromised tooth/teeth }\end{array}$ \\
\hline Study design & Prospective-clinical-intervention. \\
\hline Intervention & Placebo-gel on the control side that contains water, thickener, preservative, sorbitol \\
and a small amount of peppermint.
\end{tabular}


Table 1. Cont.

\begin{tabular}{|c|c|}
\hline $\begin{array}{l}\text { Randomization of patients into treatment } \\
\text { and control group }\end{array}$ & $\begin{array}{l}\text { A computer software program was used to code each participant for the NBFG and } \\
\text { placebo-gel application to avoid bias. }\end{array}$ \\
\hline NBFG application & $\begin{array}{l}\text { Initially a trained dental assistant applied the NBFG and placebo-gel followed by } \\
\text { training of the patients by a dental assistant. The patients were instructed to follow the } \\
\text { same protocol. }\end{array}$ \\
\hline Pain perception & $\begin{array}{l}\text { The numerical rating scale (NRS) questionnaire was used to measure PP. The } \\
\text { numerical scale consisted of segments ranging from } 0 \text { to } 10 \text {, with } 0 \text { being "no pain" } \\
\text { and } 10 \text { being "the worst pain imaginable". The participants picked (verbal version) or } \\
\text { drew a circle around (written version) the number that best describes the pain } \\
\text { dimension, usually intensity. A trained dental assistant recorded initial baseline data } \\
\text { (T1), immediately after case and control selection. The participants were asked to } \\
\text { record pain on both sides (active and placebo side) using } 2 \text { sets of questionnaires at the } \\
\text { 7th day (T2) and the 28th day (T3). In addition, telephone calls / message were made } \\
\text { on the 7th day and the 28th day (T3) to ensure collection of data. }\end{array}$ \\
\hline Statistical analysis & $\begin{array}{l}\text { Statistical analysis was performed using IBM SPSS Statistics version } 22.0 \text { (IBM Co., } \\
\text { Armonk, NY, USA). The mean rank values of PP among the } 2 \text { groups were obtained by } \\
\text { descriptive analysis. Mann-Whitney U-test was used to compare the level of PP } \\
\text { between the } 2 \text { groups and disparities between time points, i.e., T1, T2, and T3. } \\
\text { Spearman correlation test was used to evaluate the correlation between PP and time of } \\
\text { application of active and placebo-gel. }\end{array}$ \\
\hline
\end{tabular}

\section{Results}

The mean age of the participants was $17.5( \pm 1.54)$, with 15 females and 17 males. A Mann-Whitney test indicated that there was no significant difference in the PP scores at $\mathrm{T} 1$ point of evaluation for the placebo and active groups ( $\mathrm{Mdn}=32.50)$. However, $\mathrm{PP}$ scores were significantly different at T2 point of evaluation for the active group and placebo groups were $\mathrm{Mdn}=18.91$ and $\mathrm{Mdn}=46.81$, respectively, at the end of the 1st week after treatment, $\mathrm{U}=54, \mathrm{z}=-6.302, p<0.00$. Similarly, at the end of the 4 th week after treatment, there was a significant difference in PP scores at T3 point of evaluation for the active group $(\mathrm{Mdn}=17.19)$ and placebo group $(\mathrm{Mdn}=47.81)$, thus indicating a predictable beneficial effect of the active group $U=22, z=-0.6730, p<0.00$. The results of mean rank score in the active group indicate that the pain perception reduced over time, i.e., from T1 to $\mathrm{T} 3$, suggesting a reduction of pain perception by the participants over a period of time (Figure 1 and Table 2).

A Pearson correlation coefficient was computed to assess the relationship between the $\mathrm{PP}$ in the active and placebo groups over time from T1, T2, and T3. A positive correlation between the two variables, $\mathrm{r}=0.985, n=32, p=0.05$, was observed. These findings summarize the results (Table 3). Overall, there was a strong, positive correlation between time and the active and placebo groups. Increases in the time of application of active gel were correlated with increased reduction in PP.

Table 2. PP in active vs. placebo group in T1, T2, and T3 (Mann-Whitney U-test).

\begin{tabular}{cccc}
\hline ( $\boldsymbol{n}=\mathbf{6 4})$ & $\mathbf{T 1}$ & $\mathbf{T 2}$ & T3 \\
\hline Mann-Whitney U & 512 & 54 & 22 \\
Wilcoxon W & 1040 & 582 & 550 \\
Test Static & 512 & 54 & 22 \\
Standard Error & 71.49 & 72.67 & 72.80 \\
Standardized Test Statistic & 0.000 & -6.302 & -6.730 \\
Asymptotic Sig. (2-sided test) & 1.000 & $<0.001 *$ & $<0.001 *$ \\
\hline
\end{tabular}


Table 3. Spearman correlation of active group and placebo group over a period of T1, T2, and T3 intervals.

\begin{tabular}{|c|c|c|c|c|c|c|}
\hline$n=64$ & $\begin{array}{l}\text { Active Group } \\
\text { (T1) }\end{array}$ & $\begin{array}{l}\text { Active Group } \\
\text { (T2) }\end{array}$ & $\begin{array}{l}\text { Active Group } \\
\text { (T3) }\end{array}$ & $\begin{array}{c}\text { Placebo Group } \\
\text { (T1) }\end{array}$ & $\begin{array}{l}\text { Placebo Group } \\
\text { (T2) }\end{array}$ & $\begin{array}{c}\text { Placebo Group } \\
\text { (T3) }\end{array}$ \\
\hline Active group (T1) & 1 & & & & & \\
\hline Active group (T2) & $0.557 * *$ & 1 & & & & \\
\hline Active group (T3) & $0.380 *$ & $0.529 * *$ & 1 & & & \\
\hline Placebo group (T1) & $1.000 * *$ & $0.557 * *$ & $0.380 *$ & 1 & & \\
\hline Placebo group (T2) & 0.304 & 0.108 & -0.001 & 0.304 & 1 & \\
\hline Placebo group (T3) & 0.220 & 0.096 & -0.032 & 0.220 & $0.817^{* *}$ & 1 \\
\hline
\end{tabular}

${ }^{*}$. Correlation is significant at the 0.05 level (2-tailed). ${ }^{* *}$. Correlation is significant at the 0.01 level (2-tailed).

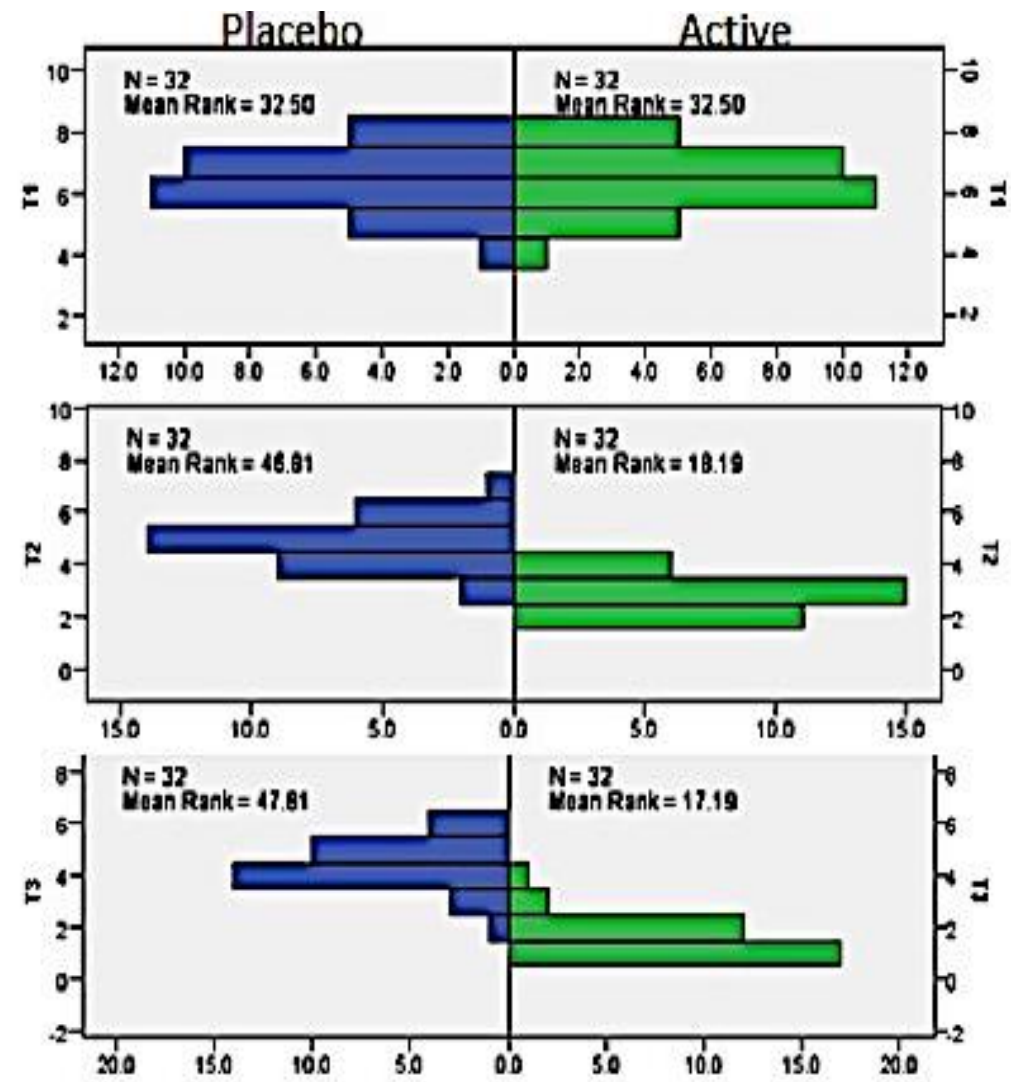

Figure 1. Mean rank of PP in active vs. placebo group in T1, T2, and T3.

\section{Discussion}

Orthodontic appliances are attached to a sensitive area of the body, resulting in both physical and psychological discomfort, which can exaggerate undesirable influence on patients' aspiration to undergo treatment [10]. Based on present literature review emphasis on investigators' points of view, little attention has been given to patients' $\mathrm{PP}$ and discomfort [11,12]. NBFG is a highly efficient nano-bio fusion gel, produced for the first time, with a new technology named nano-bio fusion. The main components of this gel are, namely, Vitamin C, Vitamin E, and propolis extract, which are bio-compatible nanoemulsion agents, with antibacterial, anti-inflammatory and anti-oxidative effect. Vitamin C and Vitamin E have a powerful antioxidant effect and propolis, which content flavonoids. Hence, the present study investigated the effect of NBFG in PP in FOTIG.

Koo et al. [13] proposed that propolis in mouth rinse formulation can significantly reduce the Plaque Index obtained on the 4th day of the study. Coutinho demonstrated marked improvement in both microbiological and clinical parameters when propolis was used as subgingival irrigation after an interval period of 6 weeks [14] A recent study revealed promising results in clinical parameters after topical application with NBF in patients with gingivitis [15]. In the present study, between the placebo group and the active 
group, significantly decreased severity of PP was revealed in the active group. Diminutions in PP during FOTIG may have been due to a decrease in inflammatory mediators and the number of interleukins from the antioxidant component of the NBFG [16,17]. In in vivo studies, the essential oil element may also be a reason to improve PP [18].

A remarkable discovery of the current study was the relationship between pain and the time of application of active gel (T1 to T3). Pain and discomfort are seen during FOTinduced tooth movement, which has been reported that the fear of pain is a key factor dissuading patients from seeking FOT [19]. Recent reports demonstrated that the intensity of pain during 4 to $24 \mathrm{~h}$ after adjusting the appliance is very high but later on diminishes to normal by the 7th day $[7,20]$. Hence, during the period of high-intensity pain for the first 7 days, the application of NBFG was justified. In the present study, the application of NBFG was continued till the 28th day for the management of FOTIG. Hence, patients can adjust to PP and discomfort with the FOT progression, as the problems completely stop or at least terminate to be the focus of attention.

Propolis in NBFG formulations has been investigated; the results obtained from various trials are not comparable, due to the difference in composition of propolis, formulations, and the different study design used for the evaluation of its diverse activities. Based on these early considerations, it is possible to speculate that hyaluronic acid and lactoferrin, in addition to professional mechanical therapy, can be utilized for the residential care management of periodontal disease. However, paraprobiotics are anticipated to provide the most significant effect due to their distinct and novel mechanism of action based on immunomodulation [21]. The present study with the usage of NBFG in FOTIG is the first of its own kind. The PP of the patients improved significantly in all the sites irrespective of the treatment rendered compared to placebo.

The main drawback of this study is that it solely looked at pain perception using NAS. More strong measures of pain-related function and quality of life would considerably benefit more standardized pain assessments in routine care. In terms of the study's external validity, the results reported here cannot be generalized to different stages of gingivitis other than those evaluated in our procedure. Furthermore, confounding factors such as gender, age, and level of orthodontic therapy should be taken into account. In reality, individual pain thresholds, the quantity of the force applied, current emotional state and stress, cultural variations, and previous pain experiences could impact the current study's findings. Finally, the better results obtained after using the NBFG with its specific mechanism of action should be studied further, even from an immunological standpoint. To have a better knowledge of the efficacy of NBFG in pain management, further research with a larger sample size is required.

\section{Conclusions}

The present study revealed that the use of NBFG is an effective means of improvement in PP in FOTIG.

Author Contributions: Conceptualization, M.K.A., K.K.G., A.M., S.M.M., N.B.J. and A.A.S.; methodology, M.K.A., K.K.G.; software, M.K.A., K.K.G.; validation, M.K.A., K.K.G.; formal analysis, M.K.A., K.K.G., N.B.J. and A.A.S.; investigation, M.K.A., K.K.G.; resources, M.K.A., K.K.G., A.M. and S.M.M.; data curation, M.K.A., K.K.G.; writing—original draft preparation, M.K.A., K.K.G.; writing—review and editing, M.K.A., K.K.G., A.M., S.M.M., N.B.J. and A.A.S.; funding acquisition, M.K.A. All authors have read and agreed to the published version of the manuscript.

Funding: The authors appreciate the Deanship of Scientific Research, Jouf University, for granting funding to support this work (grant No. DSR-2021-01-0387).

Institutional Review Board Statement: Approval was obtained from the Ethical Committee of Jouf University (LCBE\#15-18-9/40), which complies with the Declaration of Helsinki. Strengthening the Reporting of Observational Studies in Epidemiology (STROBE) guidelines were followed to design and conduct the study. 
Informed Consent Statement: Written informed consent was obtained from all the subjects (one of the parents, either father and/or mother or legal guardian for adolescent subjects).

Data Availability Statement: The data used to support the findings of this study are included in the article. Readers can access the data supporting the conclusions of the study upon personal request.

Acknowledgments: The authors acknowledge the Deanship of Scientific Research, Jouf University, for funding this research project (grant No. DSR-2021-01-0387).

Conflicts of Interest: The authors declare no conflict of interest.

\section{References}

1. Krukemeyer, A.M.; Arruda, A.O.; Inglehart, M.R. Pain and orthodontic treatment: Patient experiences and provider assessments. Angle Orthod. 2009, 79, 1175-1181. [CrossRef]

2. Liu, Y.; Zhang, Y.; Wang, L.; Guo, Y.; Xiao, S. Prevalence of Porphyromonas gingivalis four rag locus genotypes in patients of orthodontic gingivitis and periodontitis. PLOS ONE 2013, 8, e61028. [CrossRef]

3. Lv, D.; Zhang, J.; Gu, X.; Shen, H.; Shao, S.; Hou, W.; Wang, K.; Svensson, P.; Chen, W. Transient Pain Following Orthodontic Fixed Appliances Induces Sensitization of Gingival and Periodontal Tissues. J. Oral Facial Pain Headache 2016, 30, 228-233. [CrossRef]

4. Qadri, T.; Bohdanecka, P.; Tunér, J.; Miranda, L.; Altamash, M.; Gustafsson, A. The importance of coherence length in laser phototherapy of gingival inflammation-A pilot study. Lasers Med. Sci. 2007, 22, 245-251. [CrossRef] [PubMed]

5. Qadri, T.; Miranda, L.; Tuner, J.; Gustafsson, A. The short-term effects of low-level lasers as adjunct therapy in the treatment of periodontal inflammation. J. Clin. Periodontol. 2005, 32, 714-719. [CrossRef]

6. Morrier, J. White spot lesions and orthodontic treatment. Prevention and treatment. L'Orthodontie Fr. 2014, 85, 235-244.

7. Alam, M.K.; Ganji, K.K. Nano-Bio Fusion Gingival Gel in the management of fixed orthodontic treatment-induced gingivitis: An empirical study. Am. J. Orthod. Dentofac. Orthop. 2021, 159, 808-815. [CrossRef] [PubMed]

8. Srikanth, A.; Sathish, M.; Harsha, A.V.S. Application of ozone in the treatment of periodontal disease. J. Pharm. Bioallied Sci. 2013, 5, S89. [CrossRef]

9. Butera, A.; Gallo, S.; Maiorani, C.; Preda, C.; Chiesa, A.; Esposito, F.; Pascadopoli, M.; Scribante, A. Management of Gingival Bleeding in Periodontal Patients with Domiciliary Use of Toothpastes Containing Hyaluronic Acid, Lactoferrin, or Paraprobiotics: A Randomized Controlled Clinical Trial. Appl. Sci. 2021, 11, 8586. [CrossRef]

10. Scott, P.; Sherriff, M.; DiBiase, A.T.; Cobourne, M.T. Perception of discomfort during initial orthodontic tooth alignment using a self-ligating or conventional bracket system: A randomized clinical trial. Eur. J. Orthod. 2008, 30, 227-232. [CrossRef]

11. Bergius, M.; Kiliaridis, S.; Berggren, U. Pain in orthodontics. J. Orofac. Orthop./Fortschr. Kieferorthopädie 2000, 61, $125-137$. [CrossRef]

12. Feldmann, I.; List, T.; John, M.T.; Bondemark, L. Reliability of a questionnaire assessing experiences of adolescents in orthodontic treatment. Angle Orthod. 2007, 77, 311-317. [CrossRef]

13. Koo, H.; Cury, J.A.; Rosalen, P.L.; Ambrosano, G.M.; Ikegaki, M.; Park, Y.K. Effect of a Mouthrinse Containing Selected Propolis on 3-Day Dental Plaque Accumulation and Polysaccharide Formation. Caries Res. 2002, 36, 445-448. [CrossRef]

14. Coutinho, A. Honeybee propolis extract in periodontal treatment: A clinical and microbiological study of propolis in periodontal treatment. Indian J. Dent. Res. 2012, 23, 294. [CrossRef]

15. Chatterjee, A.; Sneha, V. Evaluate the efficacy of NBF gel as an adjunct to scaling in gingivitis-A clinical study. Periodontics 2014, 20, 543-548.

16. Chapple, I. Reactive oxygen species and antioxidants in inflammatory diseases. J. Clin. Periodontol. 1997, 24, 287-296. [CrossRef]

17. Jung, M.; Triebel, S.; Anke, T.; Richling, E.; Erkel, G. Influence of apple polyphenols on inflammatory gene expression. Mol. Nutr. Food Res. 2009, 53, 1263-1280. [CrossRef]

18. Tufekci, E.; Casagrande, Z.A.; Lindauer, S.J.; Fowler, C.E.; Williams, K.T. Effectiveness of an essential oil mouthrinse in improving oral health in orthodontic patients. Angle Orthod. 2008, 78, 294-298. [CrossRef] [PubMed]

19. Oliver, R.; Knapman, Y. Attitudes to orthodontic treatment. Br. J. Orthod. 1985, 12, 179-188. [CrossRef] [PubMed]

20. Polat, O.; Karaman, A.I. Pain control during fixed orthodontic appliance therapy. Angle Orthod. 2005, 75, $214-219$.

21. Schlagenhauf, U.; Jockel-Schneider, Y. Probiotics in the Management of Gingivitis and Periodontitis. A Review. Front. Dent. Med. 2021, 2, 61. [CrossRef] 